\section{Inflammasomes, the eye and anti-inflammasome therapy}

\begin{abstract}
Inflammasomes, key molecular regulators that play an important role in inflammation, consist of a central protein, an adaptor protein ASC (apoptosis speck-like protein) and a caspase-1 protein. Upon activation, caspase- $\mathbf{1}$ induces maturation of cytokines such as interleukin-1 $\beta$

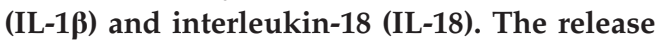
of these cytokines can result in inflammation. Inflammasomes are activated by a variety of factors and their activation involves complex signalling leading to resolution of infection, but can also contribute to the pathology of inflammatory, autoimmune, and infectious diseases. The role of NLRP1, NLRP3, NLRC4 and AIM2 inflammasomes in the pathogenesis of ocular diseases such as glaucoma, age related macular degeneration (AMD), diabetic retinopathy, dry eye and infections of the eye has been established over the past decade. In experimental studies and models, inhibition of inflammasomes generally helps to reduce the inflammation associated with these eye diseases, but as yet the role of these inflammasomes in many human eye diseases is unknown. Therefore, a need exists to study and understand various aspects of inflammasomes and their contribution to the pathology of human eye diseases. The goal of this review is to discuss the role of inflammasomes in the pathology of eye diseases, scope for antiinflammasome therapy, and current research gaps in inflammasome-related eye disease.
\end{abstract} Eye (2018) 32, 491-505; doi:10.1038/eye.2017.241; published online 24 November 2017

\section{Introduction}

An inflammasome consists of a central protein (varies with the type of inflammasome) which on activation recruits the adaptor apoptosis speck-like protein (ASC). Following this oligomerization, ASC is activated through the process of autoproteolysis, cleaving procaspase to caspase-1.1,2 Active caspase- 1 then cleaves proinflammatory cytokines prointerleukin- $1 \beta$ (IL-1 $\beta$ ) and prointerleukin-18 (IL-18) to their active forms and the release of these cytokines results in inflammation of the tissue. ${ }^{2}$ This process, including the release of the activated cytokines and activation of caspase- 1 , can lead to a process of cell death called pyroptosis. ${ }^{3}$ Pyroptosis is a form of cell death that involves the rupture of plasma membranes and subsequent release of intracellular components. Inflammasomes are known to contribute to the pathology of a variety of inflammatory, autoimmune diseases, and cancers. ${ }^{4,5}$

Innate immunity plays a central role in acute inflammation in response to microbial infection. Innate immune cells such as macrophages and dendritic cells along with epithelial and fibroblast cells mediate the immune responses to clear infection. ${ }^{6}$ However, the innate immune response is often not sufficient to clear all the pathogens. The adaptive immune response (activated by the innate immune system) can play a crucial role in clearing the infection. The adaptive immune response is complex, but results in the production of specific immunoglobulins and lymphocytes. B-cells, which produce the immunoglobulins and T-cells, can mature into memory cells, which are then available and can react quickly if stimulated by the same pathogen subsequently. ${ }^{7}$ Most nodlike receptor proteins (NLRPs) operate in innate immunity in response to a variety of microbes and sterile activators (silica, ATP, etc). The microbial molecules are recognized by Toll-like receptors (TLRs). Downstream signalling through pattern recognition receptors (PRRs) such as NLRPs is thought to be important for shaping strong adaptive immune responses.

The innate immune system employs a range of pathogen and damage sensing proteins called PRRs. ${ }^{1}$ PRRs include four different families of receptors, namely TLRs, retinoic acid-inducible
School of Optometry and Vision Science, Faculty of Science, University of New South Wales, Sydney, Australia

\section{Correspondence:}

P Yerramothu, School of Optometry and Vision Science, University of New South Wales, Rupert Myers North Building, Gate 14, Sydney 2052, Australia Tel:/Fax: +61435467236. E-mail: prav.yerramothu@ student.unsw.edu.au

Received: 15 May 2017 Accepted in revised form: 28 August 2017 Published online: 24 November 2017 
gene (RIG)-I-like receptors, nod-like receptors (NLRs), and C-type (carbohydrate binding lectin domain) lectin receptors (CLRs). Most NLRs operate in innate immunity in response to a variety of microbial molecules or molecules released because of tissue damage. These molecules are recognized by TLRs. Downstream signalling through PRRs such as NLRs is thought to be important for shaping strong adaptive immune responses. ${ }^{7}$

Inflammasomes are molecular platforms, which are assembled by NLRs in response to a variety of stimuli such as pathogen associated molecular patterns, dangerassociated molecular patterns (DAMPs), ${ }^{8,9}$ or reactive oxygen species (ROS) or cellular stress. ${ }^{10}$ NLRs are intracellular microbial and danger sensing proteins. ${ }^{1}$ Phylogeny of NLRs suggests that they are conserved in the entire eukaryote kingdom. ${ }^{11}$ NLRs can be classified under the superfamily of adenosine triphosphatases. ${ }^{12}$ NLRs have three caspase activation and recruitment domains (CARDs) or pyrin domains at their aminoterminus, a nucleotide-binding and oligomerization domain (NACHT domain) and multiple leucine rich repeats (LRRs) domain. ${ }^{13}$ NLRs are composed of 14 members, NLRP1 to 14 . A total of eight proteins are included in the assembly of inflammasomes including one of six NLRPs (NLRP1, NLRP3, NLRC4, NLRP6, NLRP7, and NLRP12), one IFN $\gamma$-inducible protein absent in melanoma 2 (AIM2) protein, one RIG-I-like helicase, and oligomers of ASC proteins ${ }^{14}$ (Figure 1).

Each inflammasome is characterized by specific scaffold domains (Figure 1). NLRP-containing inflammasomes contain LRRs, AIM2-containing inflammasomes contain HIN200 (hemopoietic expression, interferon-inducibility, nuclear localization) domains and RIG-I-containing inflammasomes have a pyrin domain (PYD). Upon activation the LRRs autophosphorylate and active LRRs recruit ASC, which then leads to the recruitment of procaspase-1 (Figure 2). This complex of NACHT, LRRs, ASC and procaspase- 1 is collectively known as the inflammasome (Figure 2). CARD domains of ASC cleave procaspase- 1 to caspase- 1 . ASC is an important adaptor protein that plays a major role in the inflammasome assembly and caspase- 1 activation through CARD-CARD interactions. ${ }^{15}$ The ASC gene encodes a $22 \mathrm{kDa}$ protein with two domains, pyrin (PYD) and CARD. In the absence of ASC, caspase- 1 is not activated resulting in the failure of IL- $1 \beta$ release. Besides caspase- 1 activation, ASC is known to activate NF- $\mathrm{B}$, play a role in apoptosis via activation of caspase- 8 , and has a role in antigen presentation. ${ }^{16}$

Pro-caspase-1, which all inflammasomes cleave, belongs to the inflammatory subfamily of caspases. Caspase- 1 is a cysteine-rich protease that processes pro IL-1 $\beta$ to active IL-1 $\beta$ and pro IL-18 to active IL-18. Procaspase- 1 resides in the cytoplasm as a $45 \mathrm{kDa}$ protein, ${ }^{15}$ which upon activation generates a heterodimer of 10 and 20 kDa subunits. Caspase- 1 was first named interleukin-1 converting enzyme but later it was included in the caspase family of proteases and named caspase- 1 due to its similar homology with the ced-3 gene from Caenorhabditis elegans. ${ }^{17}$ IL-1 $\beta$ is secreted by epithelial cells, neutrophils, monocytes, macrophages, dendritic cells, ${ }^{18} \mathrm{~B}$ cells and natural killer cells (NK cells). ${ }^{19} \mathrm{IL}-1 \beta$ has a multitude of functions including triggering the expression and production of cyclooxygenase 2 (COX-2) and type 2 phospholipase $\mathrm{A}$, and the production of prostaglandins and platelet activating factor. ${ }^{19}$ IL-1 $\beta$ also triggers the formation of new blood vessels and participates in the metastasis of tumours. ${ }^{20}$ Production of IL-1 $\beta$ increases the levels of IL- 6 and cell adhesion molecules on mesenchymal and endothelial cells. ${ }^{21}$ Pro IL-1 $\beta$ can be cleaved into its biologically active form in absence of caspase- 1 . In response to sterile inflammation neutrophils secrete active IL-1 $\beta$ and this reaction is catalysed by proteinase-3, MMP (Matrix metalloproteinases)-9, and granzyme A (Figure 6). ${ }^{22}$

\section{Inflammasomes and their mechanism of action}

\section{NLRP1 inflammasome}

The NLRP1 was the first known member of the NLR family. It is also known as caspase recruitment domaincontaining protein 7 , death effector filament-forming ced4 like apoptosis protein and nucleotide-binding domain and caspase recruitment domain protein. NLRP1 is made up of four amino-terminal domains (Figure 1) namely NACHT, LRRs, PYD, function to find (FIIND) which is strictly required for the function of the NLRP1 inflammasome, ${ }^{23}$ and a CARD at its C-terminus. The NLRP1 inflammasome can be activated by a variety of stimuli such as anthrax lethal toxin, Toxoplasma gondii, bacterial muramyl dipeptide, and ATP. Upon activation, the NLRP1 protein recruits procaspase- 1 which also has a CARD domain. This complex of NLRP1, CARD, and procaspase- 1 is collectively known as NLRP1 inflammasome. The assembled inflammasome then cleaves procaspase into its active form caspase- 1 and caspase- 1 in turn cleaves pro IL- $1 \beta$ to its active form (Figure 3).

\section{NLRP3 inflammasome}

NLRP3 is the most widely studied and the best characterized of the inflammasomes. It is also known as cryopyrin, CIAS1. The NLRP3 gene is localized in chromosome 1 and encodes a protein called cryopyrin or NLRP3 protein. NLRP3 protein consists of three domains namely LRR, NACHT, and PYD (Figure 1). ${ }^{24}$ Unlike other 


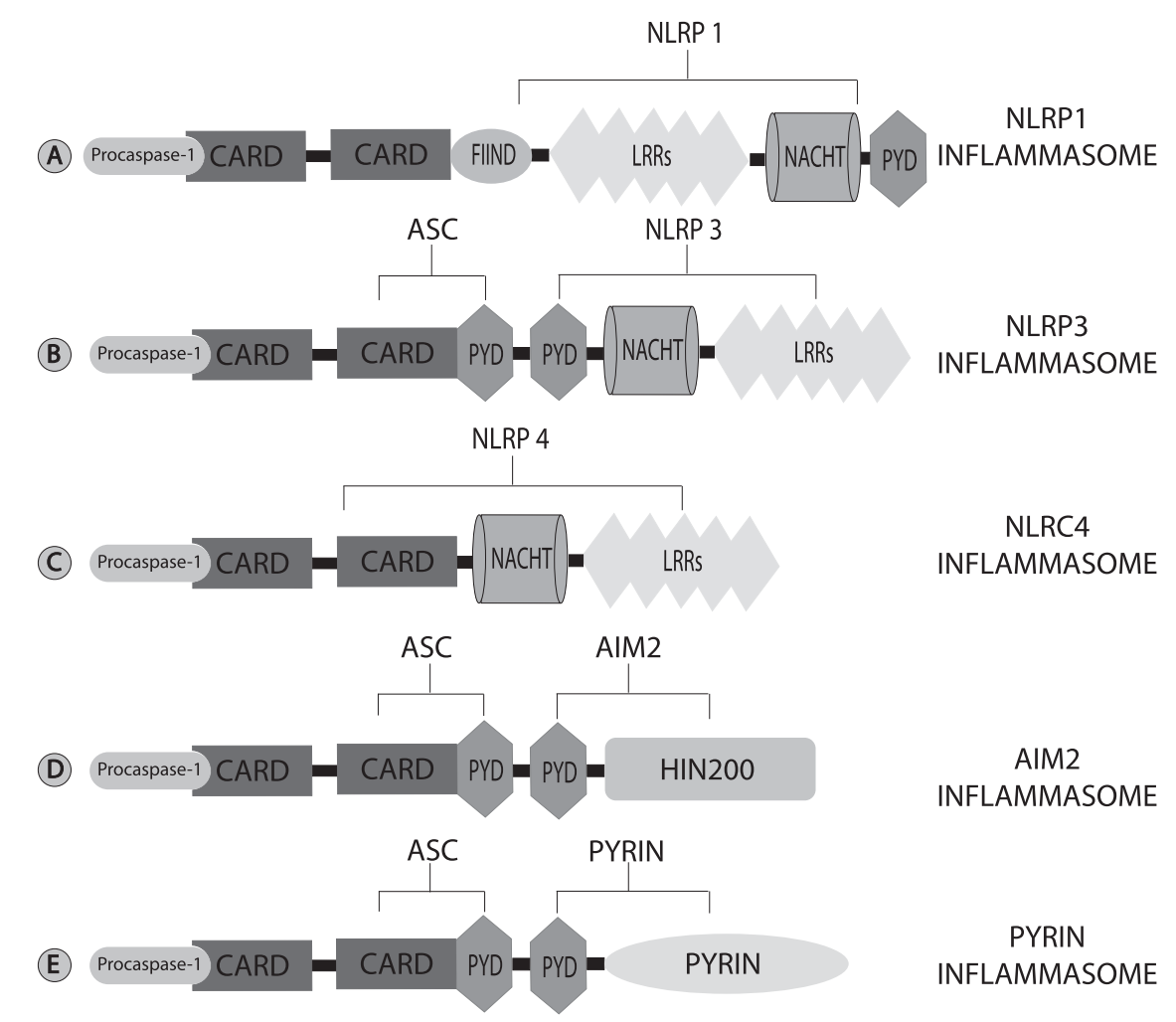

Figure 1 Structure of inflammasomes. (a) NLRP1 inflammasome has an NLRP1 protein with NACHT, LRRs, FIIND and CARD domains. (b) NLRP3 inflammasome is made up of a central NLRP3 protein. NLRP3 lacks a CARD domain; it recruits ASC to cleave procaspase-1. (c) NLRC4 inflammasome has an LRR domain at its C-terminus and lacks a pyrin domain. (d) AIM2 inflammasome contains an HIN200 domain and it recruits ASC protein to cleave procaspase-1. (e) The Pyrin inflammasome contains a central pyrin molecule and it recruits ASC to cleave procaspase- 1 .

inflammasomes, NLRP3 is activated by a variety of factors such as infection with bacteria, virus, ${ }^{25}$ fungi, ${ }^{26}$ crystalline and particulate matter ${ }^{27}$ (silica, asbestos, uric acid crystals etc), extracellular ATP, ${ }^{28}$ RNA-DNA hybrids, UVB irradiation (Figure 4). Activation of NLRP3 inflammasome requires priming by extracellular stimuli resulting in transcriptional upregulation of the inflammasome components. There is no single standard activation mechanism for the NLRP3 inflammasome but multiple models have been proposed.

In the first model, purogenic P2X7 ATP-gated ion channels are stimulated by extracellular ATP which triggers the release of $\mathrm{K}^{+}$ions leading to the recruitment of pannexin- 1 membrane pore protein to the target cell activating the NLRP3 inflammasome (Figure 4). ${ }^{29}$ In the second model, the NLRP3 inflammasome is activated upon engulfment of particles such as silica, asbestos, amyloid- $\beta$ and alum by phagocytes leading to lysosomal damage followed by cytosolic release of lysosomal contents which are sensed by the NLRP3 inflammasome by unknown mechanism (Figure 4). ${ }^{29}$ The third model suggests that all activators of NLRP3 trigger the generation of ROS which in turn activates the NLRP3 inflammasome (Figure 4). ${ }^{29}$ The source of ROS is currently unknown; however, involvement of NADPH oxidases and mitochondria are implicated. Upon activation NLRP3 recruits ASC (PY-CARD) which interacts with the CARD domain of procaspase-1. This complex of NLRP3 protein, ASC, and procaspase-1 is collectively known as NLRP3 inflammasome. Upon the assembly of this complex procaspase- 1 is cleaved to caspase- 1 and caspase- 1 cleaves proIL- $1 \beta$ into active IL- $1 \beta$ (Figure 4).

Recent reports suggest that NIMA-related kinase 7 (NEK7) is essential for the activation of NLRP3 inflammasome. ${ }^{30}$ It has been hypothesized that NEK7 is a component of NLRP3 inflammasome and directly binds to NLRP3 to control its oligomerization and ASC speck formation. ${ }^{31}$

\section{NLRC4 inflammasome}

In humans NLRC4 protein is encoded by the gene NLRC4 present on chromosome 2. NLRC4 stands for NLR, family card domain-containing protein 4 and it is also known as ice protease-activating factor (IPAF) or CARD, LRR, and NACHT-containing protein (Clan protein) or caspase recruitment domain-containing protein $12 .{ }^{32}$ The NLRC4 


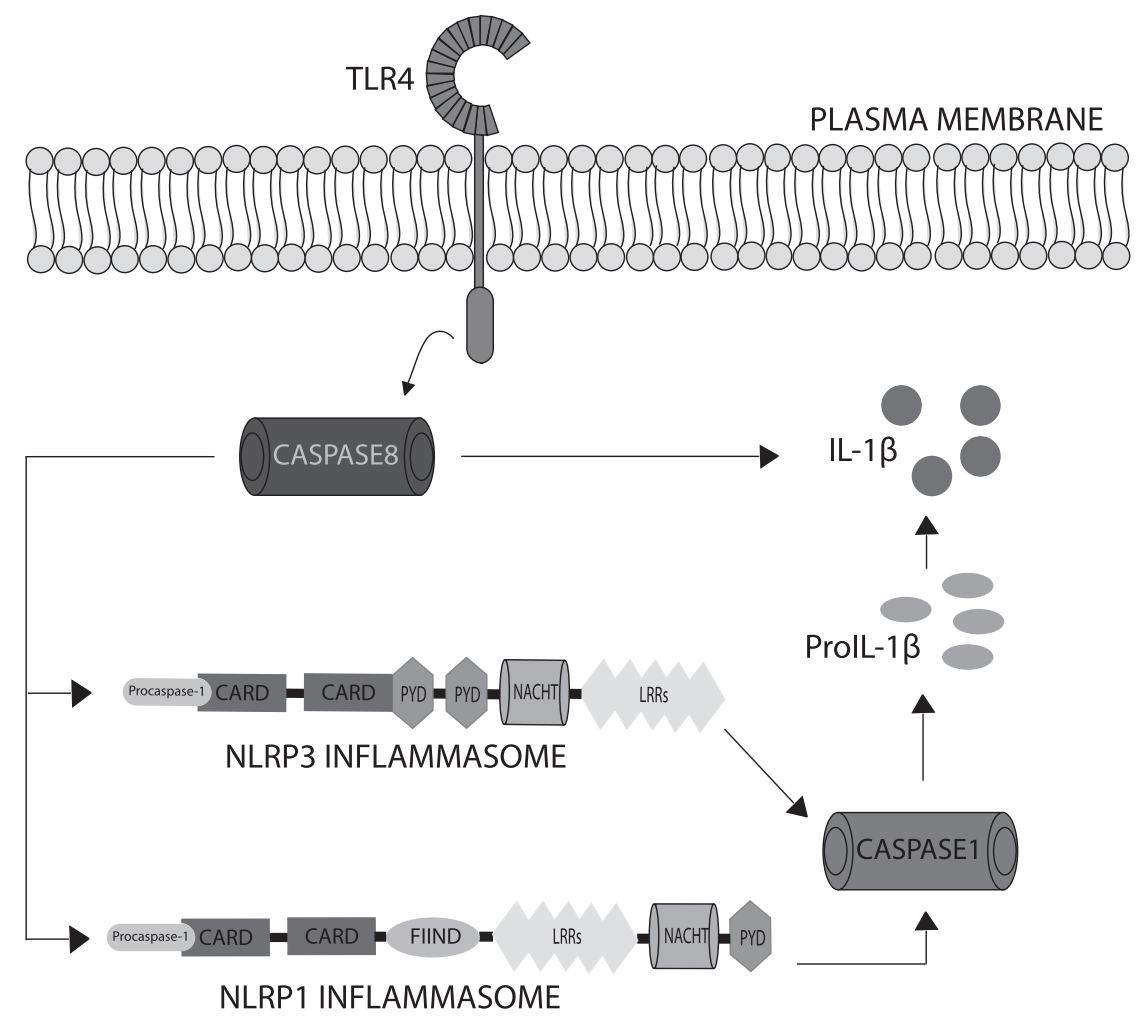

Figure 2 NLRP1 inflammasome signalling in the eye. Activation of toll like-receptor 4 in turn recruits caspase- 8 which can induce the secretion of IL- $1 \beta$ directly; alternatively caspase- 8 can activate the NLRP1 inflammasome which recruits caspase-1 to cleave pro IL-1 $\beta$ into its active form which is then transported out of the cell.

inflammasome has a NACHT domain, caspase-1, CARD and LLRs (Figure 1). Signals that activate NLRC4 include deletion of LLRs, bacterial flagellin ${ }^{33}$ and aflagellated bacteria, ${ }^{1} \beta$-arrestin, ${ }^{34}$ and type 3 secretory system (T3SS) proteins from Pseudomonas aeruginosa (Figure 5). ${ }^{35}$ To detect the inflammasome activating signals mouse NLRC4 use NLR family receptors such as apoptosis inhibitory proteins (NAIPs).$^{36}$ Binding of the antigen (activating factor) to its NAIP cognate ligand induce a conformational change leading to NLRC4 assembly (oligomerization) is initiated to cleave proIL-1 $\beta$ to its active from (Figure 5). However, it is currently unknown how CARD of NLRC4 is connected to ASC and caspase-1.

\section{AIM2 inflammasome}

The AIM2 inflammasome is a non-NLR protein that assembles an inflammasome complex in response to a variety of pathogens such as cytomegalovirus $(\mathrm{CMV})^{37}$ and Francisella tularensis. ${ }^{38}$ AIM2 has a pyrin and an HIN200 domain and ASC protein recruits pro-caspase-1 (Figure 5). Cellular FLICE (FADD-like IL-1 $\beta$-converting enzyme) caspase-8-inhibitory protein (c-FLIP) is an important macrophage survival factor that is known to play a crucial role in the activation of the AIM2 inflammasome. ${ }^{39}$ Unlike NLRs AIM2 lacks a NOD, so it employs PYD and HIN interactions to recruit ASC to cleave procaspase- 1 and proIL-1 $\beta$ to their active forms.

\section{Eye diseases and associated inflammasomes}

The human eye has a robust immune surveillance system to help combat a variety of pathogens. The eye must react and initiate an inflammatory response only when it is essential to avoid the possibility of losing vision as the result of unwarranted infammation. Inflammasomes are implicated in a variety of inflammatory, hereditary, metabolic, and systemic and eye diseases. ${ }^{15}$ Ever since the discovery of the first inflammasome, the NLRP1 in mid1990s, research has uncovered the role of inflammasomes in the pathology of cancers, infections, genetic, and autoimmune diseases. The inflammasomes NLRP1, NLRP3, NLRC4, and AIM2 have been shown to contribute to increased severity of eye diseases. On the other hand, the inflammasomes NLRP6, NLRP7, NLRP12, and PYRIN have not been shown to be involved in any eye disease to date. Activation of inflammasomes in the eye leads to inflammation which is often associated with tissue destruction. This is unlike the protective role of NLRP3 in combating infections in other tissues of the 


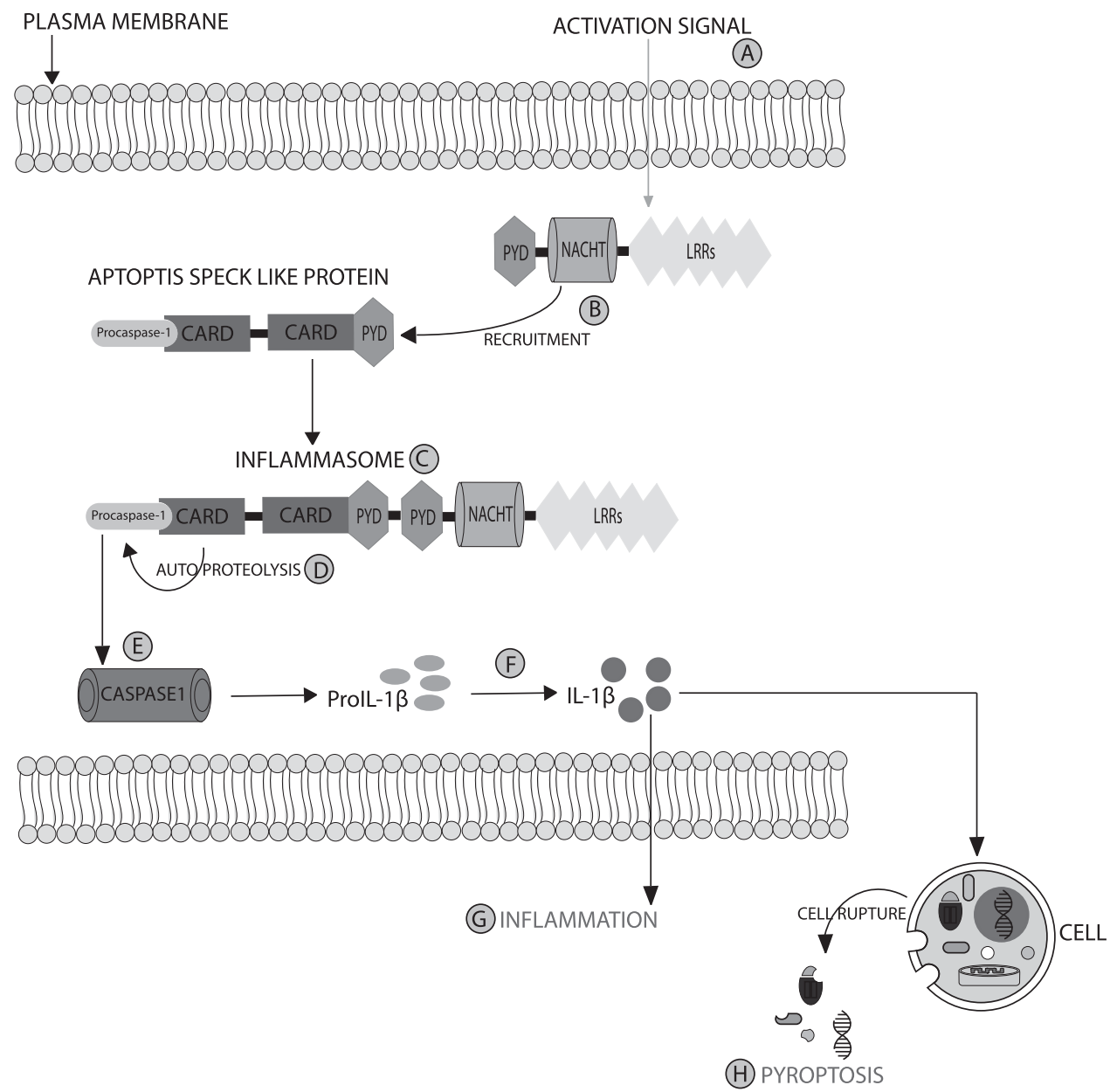

Figure 3 Activation mechanism of inflammasomes. Assembly of inflammasomes in response to activation signals and post activation effects. (a) Activation signal. (b) Recruitment of ASC by NLR. (c) Inflammasome assembly. (d) Interaction of CARD-CARD domains lead to autoproteolysis. (e) Cleavage of procaspase- 1 into caspase-1. (f) Processing of proIL-1 $\beta$ to biologically active IL- $1 \beta$ by caspase- 1 . (g) Release of IL-1 $\beta$ results in inflammation of tissue. (h) Release of IL-1 $\beta$ results in pyroptosis.

body. Thus, in the eye, therapies that inhibit the activation of inflammasomes, or the production of IL-1 $\beta$, may help improve disease outcomes. In summary, none of the inflammasomes in the eye have been shown to have a protective role. In contrast, the NLRP3 inflammasome in other tissues such as lungs has been shown to have a protective role during infection.

Activation of the NLRP3 inflammasome can protect lung tissue during infections with Mycobacterium tuberculosis, ${ }^{40}$ influenza A. ${ }^{41}$ Polymorphisms in the NLRP3 gene resulted in a lower frequency of rs10754558 G allele impairing protection against HIV $-1^{42}$ and fungal infections due to the production of a shorter form of NLRP3 protein. ${ }^{43}$ However, mutations in the NLRP3 gene that lead to increased activation of NLRP3 inflammasome and increased IL-1 $\beta$ secretion cause a set of rare hereditary autoinflammatory diseases called cryopyrin-associated periodic syndromes (CAPS) that include familial cold auto-inflammatory syndrome, Muckle-Wells syndrome
(MWS) and chronic infantile neurological, cutaneous, and articular syndrome or neonatal onset multisystem inflammatory disease. ${ }^{44}$

\section{Retinal diseases and related inflammasomes}

The inflammasomes NLRP1 and NLRP3 play crucial roles in the pathogenesis of acute glaucoma (Figure 2). ${ }^{45,46}$ Glaucoma is a progressive optic neuropathy, with the risk of increased intraocular pressure (IOP), that results in damage to retinal ganglion cells (RGCs). One study has shown increase in the NLRP3 inflammasome, caspase-1, and caspase- 8 in human glaucomatous eye compared with the normal eyes. ${ }^{47}$

In agreement with the findings from human glaucomatous eyes, NLRP3 as well as NLRP1 inflammasomes are present in mice and rat models of acute glaucoma. ${ }^{45}$ In a mouse and rat model of acute IOPinduced glaucoma, elevation of IOP activated TLR-4, 


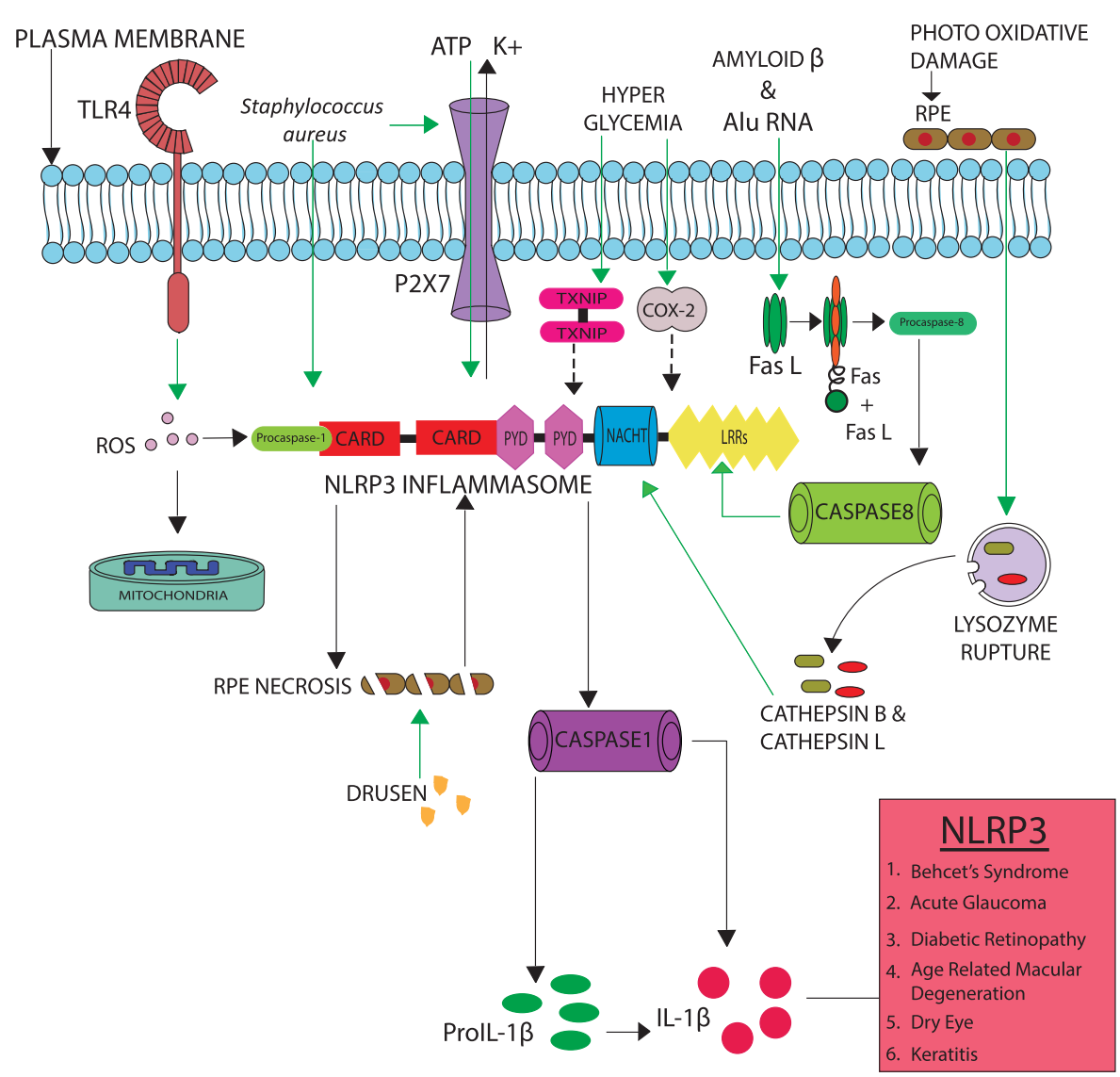

Figure 4 NLRP3 inflammasome signalling in response to various stimuli (activators represented by green arrows) assembling inflammasomes followed by the activation of caspase- 1 and subsequent maturation of IL-1 $\beta$ from its precursor.

which triggered caspase- 8 production. ${ }^{45}$ Caspase- 8 (caspase-8 functions upstream of NLRP3 inflammasome) in turn activated the NLRP1 and NLRP3

inflammasomes. ${ }^{45}$ Upon inhibition of caspase-8, levels of NLRP1 and NLRP3, ASC, caspase- 1 and IL-1 $\beta$ were significantly reduced whereas inhibition of caspase- 1 only slightly reduced IL- $1 \beta$ levels. ${ }^{45}$ However, the effect of inhibition of caspase-8-dependent inflammasome activation is yet to be studied in human acute glaucoma.

High-mobility group box 1 (HMGB1) protein also plays role in IOP-induced glaucoma. ${ }^{48,49}$ It is actively released by necrotic cells and functions as a DAMP, activating TLR-2 and TLR- $4 .{ }^{50}$ In a mouse model of acute glaucoma, rapid elevation of IOP triggered the release of HMGB1, caspase-1-dependent NLRP3 inflammasome activation and subsequent IL-1 $\beta$ production via caspase- $8 .{ }^{51,52}$ Upon HMGB1 inhibition, levels of NLRP3, caspase-8, and IL-1 $\beta$ were reduced which in turn decreased the severity of the disease by reducing the death of RGCs and decreased the reduction of retinal thickness. ${ }^{52}$ Inhibition of caspase- 8 significantly suppressed the activation of the NLRP3 inflammasome and IL- $1 \beta$ production suggesting that caspase-8 signalling is upstream of NLRP3. ${ }^{52}$ This suggests that NLRP1 and NLRP3 inflammasomes can be activated downstream of caspase- 8 signalling. ${ }^{45,52}$

In rodent models, inhibition of the NLRP1 and NLRP3 inflammasomes via intravitreal injection of caspase- 1 and caspase- 8 inhibitors reduce the severity of acute glaucoma. ${ }^{45} \mathrm{New}$ studies are required in human models of glaucoma to investigate the disease progression upon inflammasome inhibition. This could open ways for novel therapeutic targets in treating glaucoma. ROS, amyloid- $\beta$, oxidative stress, and pannexins activate inflammasomes, and these are directly linked to the pathology of human glaucoma. ${ }^{53,54}$ However, there are no studies relating these to inflammasome-mediated human glaucoma. Interactions that might occur between the NLRP1 and NLRP3 inflammasomes are yet to be characterized.

The NLRP3 inflammasome contributes to the inflammation upon partial optic nerve crush (pONC) injury in a mouse model of glaucoma. ${ }^{55}$ Levels of ASC, caspase- 1 , and IL-1 $\beta$ increase upon pONC in the retinas of mice. ${ }^{55}$ Gene knock out of the NLRP3 inflammasome in mice delayed the loss of RGCs and increased axonal survival after pONC, suggesting that the NLRP3 


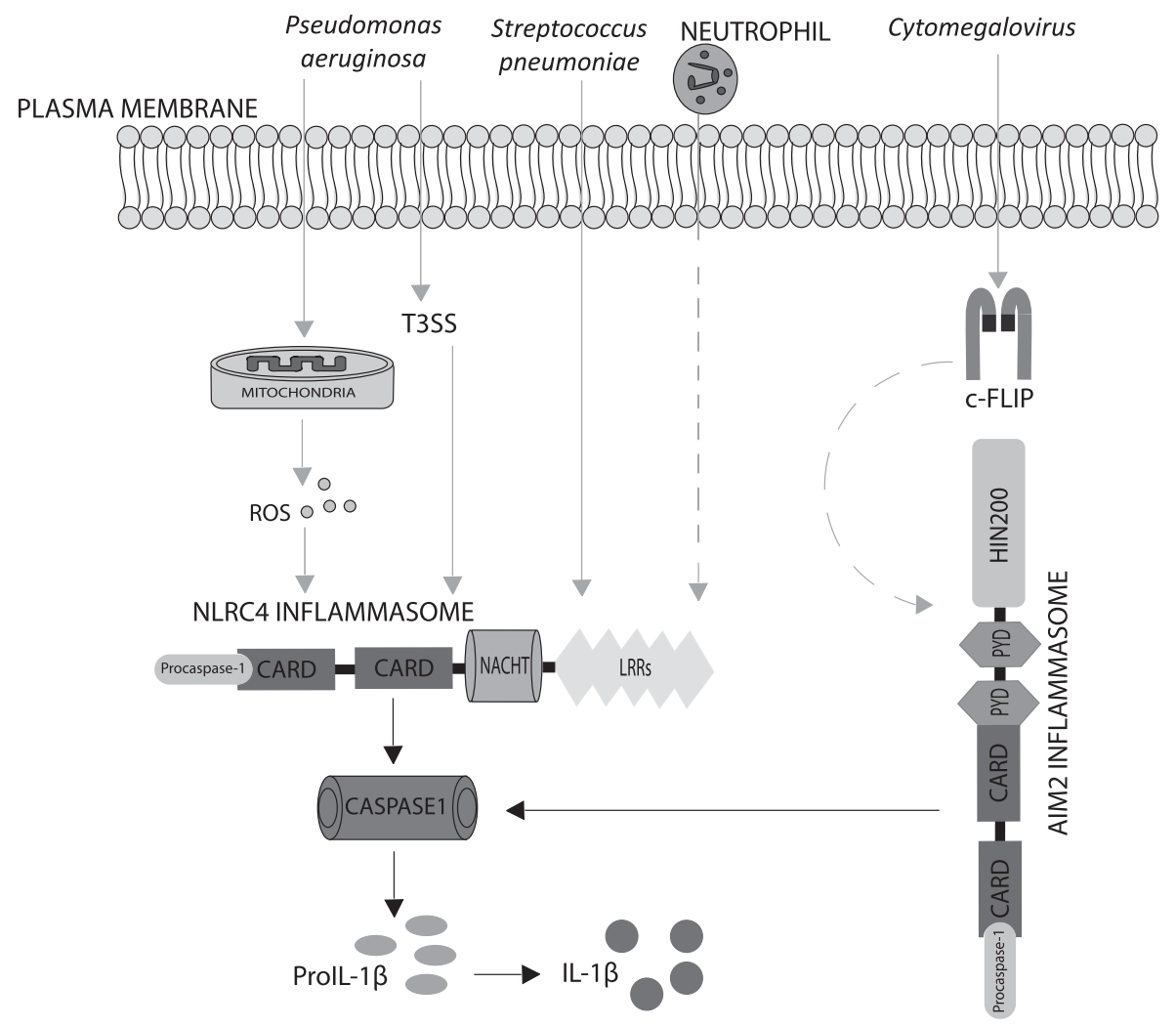

Figure 5 NLRC4 and AIM-2 inflammasomes signalling in response to various stimuli (activators represented by light grey/green arrows) assembling inflammasomes followed by the activation of caspase- 1 and subsequent maturation of IL- $1 \beta$ from its precursor.

inflammasome may be necessary for inflammation in glaucoma. ${ }^{55}$

Diabetic retinopathy is a sight threatening disease that involves the growth of blood vessels and neuroglia in the retina. Thioredoxin-interacting protein (TXNIP) is a mediator of retinal inflammation and recent evidence suggests that TXNIP levels are increased in diabetic rat retinas and in retinal cell cultures in vitro (Figure 4). ${ }^{56}$ Hyperglycaemia during diabetes can upregulate TXNIP, inducing NLRP3 expression and increasing IL-1 $\beta$ production from cultured Muller cells. ${ }^{57}$ The role played by inflammasomes in diabetic retinopathy is unclear in terms of their mechanism of action and their contribution to the disease pathology. Evidence linking

inflammasomes to diabetic retinopathy would help us to better understand the disease.

Age-related macular degeneration is a progressive sight threatening disease that results in the loss of

photoreceptors in the macula. AMD results in significant loss and damage of retinal pigment epithelium (RPE). ${ }^{58}$ In the initial stages of AMD, protein-rich extracellular deposits called drusen appear in the RPE. In AMD, the NLRP3 inflammasome is activated and its activation has been proposed to be through many factors such as drusen components, RPE and complement proteins, oxidative stress, oxidative by products and DNA (Figure 4). ${ }^{59-61}$ Deposition of drusen on RPE results in their destruction by necrosis and activation of the NLRP3 inflammasome. ${ }^{62}$ Drusen and its components such as carboxyethylpyrrole and complement protein $\mathrm{C} 1 \mathrm{q}$ (Figure 4$)^{63}$ activate the NLRP3 inflammasome in bone marrow-derived macrophages of mice and humans. ${ }^{59} \mathrm{C} 1 \mathrm{q}$ activates the NLRP3 inflammasome through the phagolysosome (a phagolysosome is formed by the fusion of a lysosome and a phagosome in the cytoplasm, the proteolytic enzymes present in the lysosome will destroy the contents ingested by the phagosome) different from proposed models of NLRP3. ${ }^{59}$

Nucleic acids such as Alu RNA (Alu DNA and RNA are repetitive nucleotide sequences that occur in the human genome and their function is yet to be fully determined) can also activate the NLRP3 inflammasome during RPE degeneration (Figure 4). Initially Alu elements were thought to be functionless entities but they are now recognized for their transcriptional regulatory functions. ${ }^{64}$ Alu RNA activates the NLRP3 inflammasome producing IL-18 followed by the apoptosis of human and mouse RPE cells. This cell death, in a Fas knock out mouse, is mediated by caspase- 8 /caspase- 3 activation through MyD88 or Fas signalling (Figure 4). ${ }^{65,66}$ Formation of 
functional NLRP3 inflammasome involves two distinct steps (Figure 4): priming (upregulation of inflammasome components) and activation (assembly of inflammasome components) ${ }^{67}$ However, it is not clearly understood how Alu RNA activates the NLRP3 inflammasome.

Studies on RPE cells following photooxidatve damage have led to the discovery of a unique way of activating the NLRP3 inflammasome. Blue light-induced photooxidative damage to RPE cells with lipofuscin deposits lead to phototoxic cell death. ${ }^{68}$ This then leads to the rupture of lysosomal membranes resulting in release of their contents into the cytosol. Lysosomal rupture activates NLRP3 along with the activation of caspase-1 and IL1- $\beta$ and IL-18 secretion. Activation of NLRP3 through lysosomal rupture was mediated by cathepsin B or cathepsin L (Figure 4). ${ }^{68}$

NLRP3 inflammasome was thought to have a protective role in AMD. In a wet AMD model that induces choroidal neovascularization (CNV) through laser treatment, genetic knockout of NLRP3 in mice had increased CNV and subretinal haemorrhaging compared to wild-type and interleukin-1 receptor knockout mice. ${ }^{59}$ Therefore, it has been proposed that the NLRP3 inflammasome has a protective role in wet AMD. However, experimental data from five different laboratories show that NLRP3 inflammasome and IL-18 has no protective role in $\mathrm{CNV}$-induced wet model of AMD. ${ }^{69}$ To address the conflicting roles of NLRP3 inflammasome and IL-18 in CNV, Hirano et al have used a standard laser-induced mouse model. ${ }^{69}$ Intravitreal injections of recombinant mouse IL-18 up to $1 \mu \mathrm{g}$ did not affect $\mathrm{CNV}$ in mice compared to placebo injections. ${ }^{69}$ Simultaneously, transfection of plasmids encoding pro and active IL-18 into RPE cells via subretinal injection in mice did not affect the CNV volume. ${ }^{69}$ These data support that IL-18 is not an anti-angiogenic factor. Furthermore, antibody targeting IL-18, used by Doyle et al ${ }^{59}$ was diluted in $50 \%$ glycerol, which is known to be proangiogenic. $^{70}$ Testing this hypothesis, intravitreal injection of glycerol alone increased $\mathrm{CNV}$ in wild-type mice and in contrast administering isotype IgG formulated in glycerol-free buffer showed no increase in CNV. ${ }^{69}$ Studies from Hirano et al also found that genetically deficient mice for either IL-18 or its receptor IL-18R1 showed reduced CNV volume compared to wildtype mice. ${ }^{69}$ However, it has been hypothesized that developmental loss of IL-18 function may create a niche that could reduce angiogenesis. ${ }^{69}$

The NLRP1 and NLRP3 inflammasomes play a vital role in retinal pathologies such as human/experimental glaucoma, AMD and diabetic retinopathy. Therapies targeting inflammasome inhibition to treat AMD are currently being tested at the level of preclinical trials. ${ }^{71}$ However, it is unclear whether the data from experimental models are translatable to humans, successful clinical trials could help us understand the therapeutic efficiency of inflammasome targeting as a treatment modality.

\section{Inflammasomes in Behcet's syndrome and dry eye disease}

The NLRP3 inflammasome has been implicated in the pathogenesis of Behcet's syndrome and dry eye disease. ${ }^{72}$ Mutations in the NLRP3 gene result in rare autoinflammatory diseases collectively known as CAPS that include familial cold autoinflammatory syndrome, MWS and neonatal onset multisystem inflammatory disease. ${ }^{44}$ The ocular inflammation associated with CAPS is due to spontaneous activation of NLRP3 inflammasome and subsequent production of IL-1 $\beta .^{73}$

Behcet's syndrome is a systemic condition characterized by recurrent uveitis and skin lesions. Macrophages from Behcet's syndrome patients in culture showed increased expression of TLR-2/4 which led to the production of ROS and mitochondrial stress ultimately activating the NLRP3 inflammasome to produce IL-1 $\beta .^{74}$ Another study that explored the possible mechanism of IL-1 $\beta$ secretion in Behcet's syndrome patients showed that mutations in NLRP3 gene could result in over production of IL-1 $\beta$ and other proinflammatory cytokines. ${ }^{75}$ These mutations are inherited by the patients that effect the spec formation (accumulation and bonding of large number of ASC proteins) of ASC protein leading to over production of IL- $1 \beta .^{75}$ The association of circulating immune complexes and complement activation with Behcet's syndrome is evident and the complement system is known to activate inflammasome. ${ }^{76}$ However, there is no evidence directly linking inflammasomes and complement activation to Behcet's syndrome.

Dry eye disease is characterized by inflammation of the ocular surface and increased tear osmolarity causing symptoms of ocular discomfort. ROS generated in response to extended dryness activates the NLRP3 inflammasome in a murine dry eye model. ${ }^{72}$ ROS-induced NLRP3 activation led to the production of IL-1 $\beta$ through caspase-1 activation. ${ }^{72}$ Conjunctival goblet cell density can be used as a marker for dry eye disease. ${ }^{77}$ When goblet cells in the conjunctiva were exposed to Staphylococcus aureus, the NLRP3 inflammasome was activated. ${ }^{78}$ Immunohistochemical analysis has shown that components of the NLRP3 inflammasome are present in human and rat conjunctival goblet cells along with the purinergic receptors $\mathrm{P} 2 \mathrm{X} 4$ and $\mathrm{P} 2 \mathrm{X} 7$, and TLR-2. ${ }^{78}$ This suggests that $S$. aureus activates NLRP3 inflammasome through purinergic receptors with subsequent secretion of IL-1 $\beta$ (Figure 4) ${ }^{78}$ Current options for immunotherapy for dry eye include cyclosporine A and topical 
corticosteroids. Topical application of inflammasome inhibitors could serve as alternative treatment modalities for current dry eye therapies.

\section{Infections of the eye and related inflammasomes}

Infection plays important role in assembling inflammasomes through DAMPs/TLR signalling. A variety of inflammasomes are assembled in response to bacterial, viral, fungal, and parasitic infections of the eye. Mouse and rat macrophages infected with Toxoplasma gondii trigger NLRP1-mediated inflammatory responses. ${ }^{79}$ The exact mechanism through which T. gondii activates the NLRP1 inflammasome is yet to be resolved, but the NLRP1 inflammasome generates a protective response against $T$. gondii when mice are orally infected. ${ }^{79}$ Caspase1/11-mediated signalling appears to be involved in clearing the pathogen in the mouse model. ${ }^{79}$

The NLRC4 inflammasome is activated during corneal ulceration caused by Streptococcus pneumoniae and Pseudomonas aeruginosa. ${ }^{80,81}$ The inflammasome is present at 1000 -fold greater levels in ulcerating corneas when compared with control eyes. ${ }^{80}$ Toxins secreted by $P$. aeruginosa (exoS, exoT, and exoU) and pneumolysin of S. pneumoniae can activate the NLRP3 and NLRC4 inflammasomes (Figure 5)..$^{32}$ Pneumolysin is a known ligand for TLR4 and activation of NLRP3 may occur via TLR4 signalling. ${ }^{82}$ A similar mechanism could also activate the NLRC4 inflammasome. ${ }^{83}$ During infection, assembly of the inflammasome indirectly via IL-1 $\beta$ attracts inflammatory mediators such as cytokines and chemokines. ${ }^{84-86}$ In this processes of eliminating the pathogen collateral damage occurs to host tissue resulting in partial or permanent blindness.

In a mouse model of $P$. aeruginosa keratitis, inhibition of caspase- 1 has been studied as an adjuvant therapy with ciprofloxacin. ${ }^{87}$ Inhibition of caspase-1 and killing the bacteria in combination with ciprofloxacin reduced the severity of corneal inflammation. ${ }^{87}$ Inhibition of inflammasome complex (caspase-1) could serve as an adjuvant therapy in targeting infectious and inflammatory diseases of the eye. It could be possible that caspase- 1 activation in this model is NLRC4 inflammasome dependent. IL-1 $\beta$ is a pro-inflammatory cytokine contributing to the pathogenesis of bacterial keratitis. Murine models of keratitis have shown that IL-1 $\beta$ levels are upregulated from $4 \mathrm{~h}$ post infection. ${ }^{84,88}$ IL-1 $\beta$ is a potent pro-inflammatory cytokine that can induce activation and upregulation of VEGF, ${ }^{89}$ ICAM- 1,90 IL-8 (MIP-2 mouse analogue of human IL-8) a major chemoattractant, CXC chemokine receptor $2^{84}$ and other neutrophil activating chemokines facilitating the entry of neutrophils into the cornea.
MMPs are protein-cleaving enzymes that degrade the components of basement membrane. Gelatinases MMP-2 and MMP-9 are widely studied in the eye as they selectively degrade type IV collagen. ${ }^{91}$ IL-1 is known to induce the production of MMP- $9{ }^{92}$ which can process the maturation of pro-IL-1 $\beta$ into active IL-1 $\beta$ (inflammasome independent as shown in Figure 6). ${ }^{22}$ MMP-9 also plays important role in ulcerative keratitis, important regulator of corneal pathology and corneal wound healing by helping the neutrophils to transmigrate into the cornea. ${ }^{85,93}$ Neutrophils and monocytes are the main source of MMP-9 during corneal infections. MMP-9 mediates its chemotactic effects via chemokine receptors CXCR1 and CXCR2. ${ }^{86}$ There exists a direct relation between MMP-9 and IL-1 $\beta$, mice (uninfected) treated with IL-1 $\beta$ neutralizing antibody showed significant reduction in MMP-9 and the vice versa is true. ${ }^{85}$ Mice injected with MMP-9 neutralizing antibody showed reduced PMNs compared to controls suggesting regulatory role of PMN transmigration into the cornea. All these data suggest that production of IL-1 $\beta$ controls the induction of many cytokines and chemokines including MMP-9 in the corneal disease. It could be hypothesized that both inflammasome dependent and independent production of MMP-9 can influence pathology of the corneal infections.

A recent study has brought to light a novel mechanism by which the NLRC4 inflammasome can be activated through mitochondria. Infecting bone marrow-derived macrophages with $P$. aeruginosa resulted in the release of mitochondrial DNA and ROS (Figure 5). ${ }^{94}$ Inhibition of ROS reduced the production of mitochondrial DNA. ${ }^{94}$ Mitochondrial DNA can activate the NLRC4 inflammasome in bone marrow-derived macrophages. ${ }^{94}$ Another interesting mechanism through which the NLRC4 inflammasome can be activated is by pilin. In mouse macrophages, NLRC4 inflammasome can be activated by Type IV pilin of P. aeruginosa. ${ }^{95}$ Pseudomonas species are commonly seen in corneal infections; however, very little is understood about inflammasome activation by $P$. aeruginosa in the eye. It could be hypothesized that ROS and type IV pilin could activate NLRC4 inflammasomes in corneal infections.

The AIM2 inflammasome is a non-NLR protein that assembles an inflammasome complex in response to a variety of pathogens such as $\mathrm{CMV}^{37}$ and Francisella tularensis. ${ }^{38}$ AIM2 has a pyrin and an HIN200 domain and an ASC protein which recruits pro-caspase-1(Figure 1). Cellular FLICE (FADD-like IL-1 $\beta$-converting enzyme) caspase-8-inhibitory protein (c-FLIP) is an important macrophage survival factor that is known to play a crucial role in the activation of the AIM2 inflammasome (Figure 5). ${ }^{39}$ The AIM2 inflammasome can be activated in 
(1)
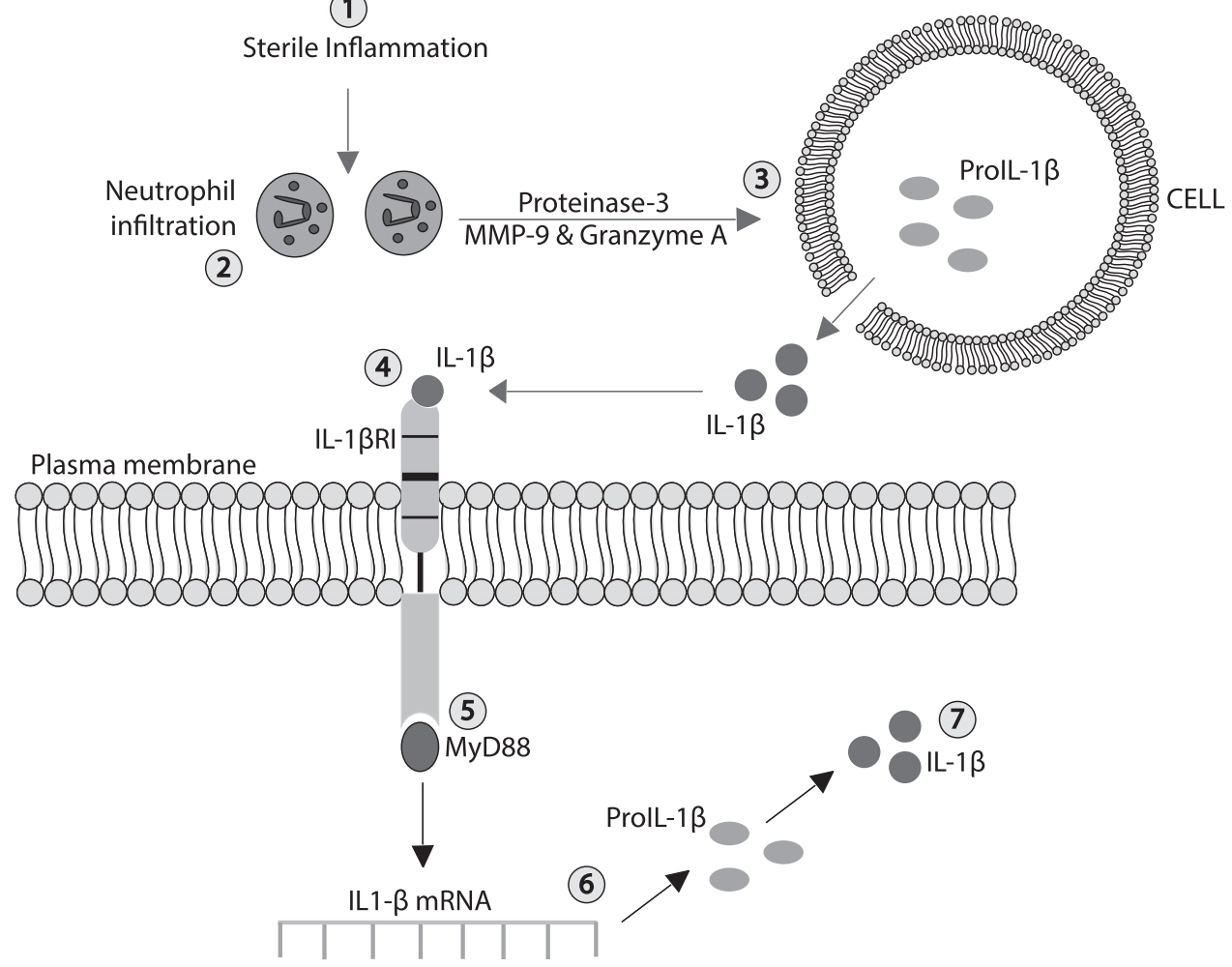

Figure 6 Caspase-1 independent regulation of IL-1 $\beta$ in the body: (signalling with light grey/red arrows). (1) Sterile inflammatory conditions such as fever are followed by neutrophil infiltration (2) which can produce IL-1 $\beta$. (3) Enzymes such as proteinase-3, MMP-9 and granzyme A cleave proIL- $1 \beta$ into its active form. (4) Free IL-1 $\beta$ binds to its transmembrane receptor IL- $1 \beta R$ I. (5) Binding of IL- $1 \beta$ to its receptor results in the recruitment of an adaptor protein MyD88. (6) MyD88 induces the production of IL-1 $\beta$ mRNA in the cytosol and subsequent production of pro IL-1 $\beta$ protein. (7) Caspase-1 cleaves pro IL-1 $\beta$ into its active form which is transported out of the cell.

a murine model of experimental CMV retinitis (Figure 4). CMV retinitis in humans accounts for up to $30 \%$ of the visual impairment in acquired immuno deficiency syndrome (AIDS) patients. ${ }^{96}$ This condition not only manifests in AIDS patients but also in over severe types of immunocompromised patients, but usually with a lower incidence. ${ }^{97}$ Mice infected with CMV after 10 weeks developed severe retinitis and pyroptosis involving cytokines such as TNF- $\alpha$ and IL- $1 \beta$ and the AIM2 inflammasome. The AIM2 inflammasome may be activated in response to double stranded DNA from CMV (Figure 5). ${ }^{98}$

Research has uncovered major molecular mechanisms behind the inflammasomes assembly during infections; however, there is no clinical evidence linking the role of inflammasomes in human eye infections. Much of the evidence available on inflammasome assembly is from cell culture and experimental models in animals. Therefore, a need exists to understand the role of inflammasomes in human eye diseases. This could result in the design of new classes of therapeutic agents to combat infectious and inflammatory diseases.

\section{Conclusion}

Certain inflammasomes play crucial roles in posterior and anterior eye diseases. Recent reports on the function of inflammasomes in the eye have brought novel mechanisms to light involved in these processes. However, the exact role of inflammasomes and their interacting ligands in human eye diseases are yet to be fully elucidated. Use of caspase-1 inhibitors has shown promising results in reducing the severity of certain eye diseases. Understanding the role of inflammasomes in human eye diseases could help the design effective therapies aiding clinical practice. Although many inhibitors of inflammasomes have been discovered (Table 1), they are yet to be tested in human or animal models of eye diseases. These should be tested in relevant animal models of eye diseases and this may lead to the development of novel treatments for inflammatory, autoimmune and infectious eye diseases respectively. Understanding the role of inflammasomes and IL-1 led to the successful development of anti-inflammasome therapies targeting IL-1 and its receptor IL-1R. Few examples include Anakinra targeting IL-1R1 and 


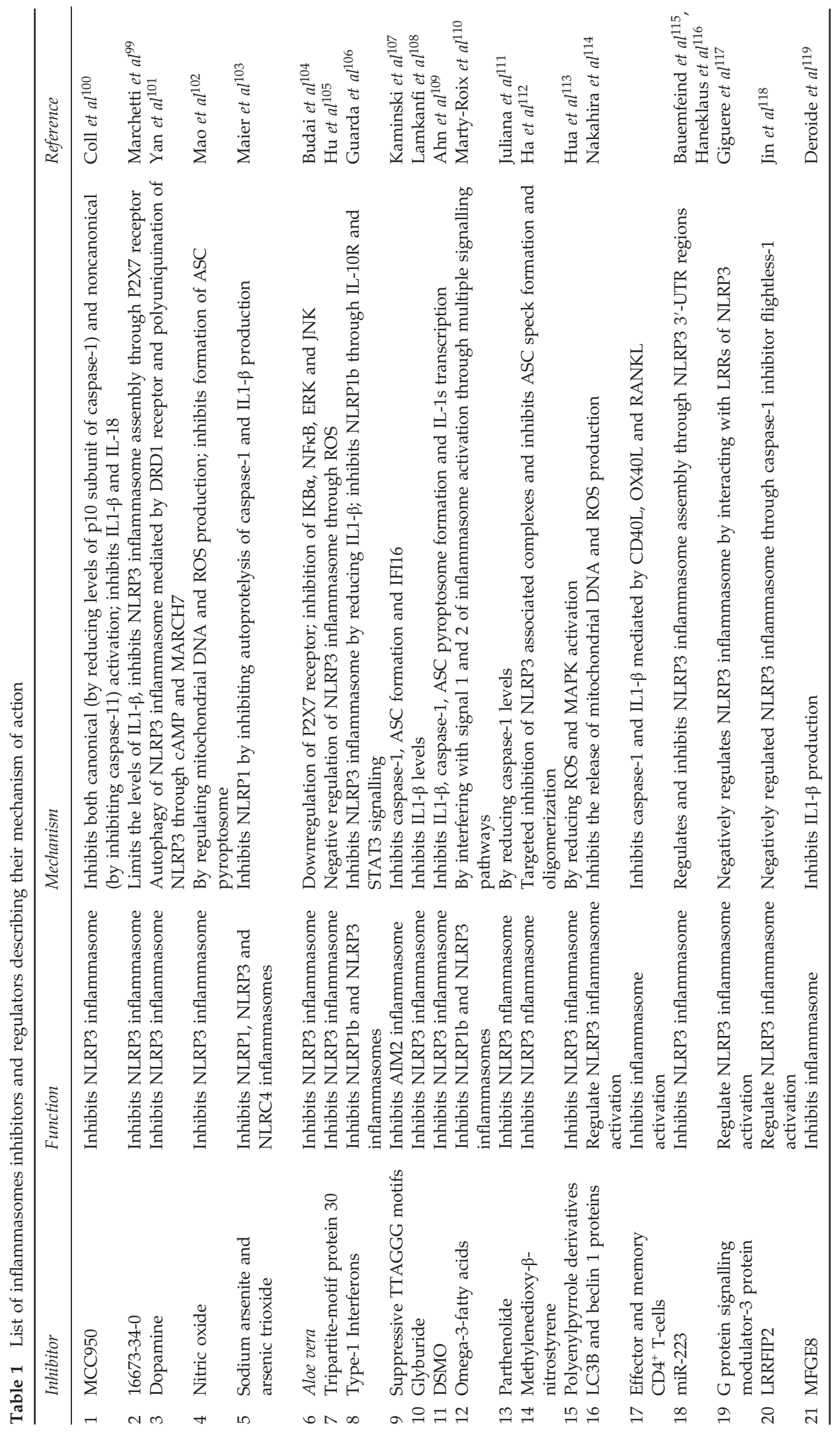


Canakinumab and IL-1 $\beta$ antagonist to treat CAPS. ${ }^{99}$ With recent advances in eye research anti-inflammasome therapies are now being translated at the level of clinical trials for diseases such as AMD.

\section{Conflict of interest}

The authors declare no conflict of interest.

\section{References}

1 Davis BK, Wen H, Ting JP. The inflammasome NLRs in immunity, inflammation, and associated diseases. Ann review immunol 2011; 29: 707-735.

2 Conforti-Andreoni C, Ricciardi-Castagnoli P, Mortellaro A. The inflammasomes in health and disease: from genetics to molecular mechanisms of autoinflammation and beyond. Cell mol immunol 2011; 8(2): 135-145.

3 Dinarello CA. Interleukin-1 beta, interleukin-18, and the interleukin-1 beta converting enzyme. Ann NY Acad Sci 1998; 856: 1-11.

4 Lee HM, Kim JJ, Kim HJ, Shong M, Ku BJ, Jo EK. Upregulated NLRP3 inflammasome activation in patients with type 2 diabetes. Diabetes 2013; 62(1): 194-204.

5 Dinarello CA. Why not treat human cancer with interleukin-1 blockade? Cancer metastasis rev 2010; 29(2): 317-329.

6 Robinson MJ, Sancho D, Slack EC, LeibundGut-Landmann $\mathrm{S}$, Reis e Sousa C. Myeloid C-type lectins in innate immunity. Nat immunol 2006; 7(12): 1258-1265.

7 Takeuchi O, Akira S. Pattern recognition receptors and inflammation. Cell 2010; 140(6): 805-820.

8 Maslanik T, Mahaffey L, Tannura K, Beninson L, Greenwood BN, Fleshner M. The inflammasome and danger associated molecular patterns (DAMPs) are implicated in cytokine and chemokine responses following stressor exposure. Brain Behav Immun 2013; 28(0): 54-62.

9 Savage CD, Lopez-Castejon G, Denes A, Brough D. NLRP3inflammasome activating DAMPs stimulate an inflammatory response in glia in the absence of priming which contributes to brain inflammation after injury. Front Immunol 2012; 3: 288.

10 Lamkanfi M, Dixit VM. Mechanisms and functions of inflammasomes. Cell 2014; 157(5): 1013-1022.

11 Jones JD, Dangl JL. The plant immune system. Nature 2006; 444(7117): 323-329.

12 Bonardi V, Cherkis K, Nishimura MT, Dangl JL. A new eye on NLR proteins: focused on clarity or diffused by complexity? Curr Opin Immunol 2012; 24(1): 41-50.

13 Martinon F, Tschopp J. NLRs join TLRs as innate sensors of pathogens. Trends Immunol 2005; 26(8): 447-454.

14 Yu M, Levine SJ. Toll-like receptor, RIG-I-like receptors and the NLRP3 inflammasome: key modulators of innate immune responses to double-stranded RNA viruses. Cytokine growth factor rev 2011; 22(2): 63-72.

15 Di Virgilio F. The therapeutic potential of modifying inflammasomes and NOD-like receptors. Pharmacol Rev 2013; 65(3): 872-905.

16 Ippagunta SK, Malireddi RK, Shaw PJ, Neale GA, Vande Walle L, Green DR et al. The inflammasome adaptor ASC regulates the function of adaptive immune cells by controlling Dock2-mediated Rac activation and actin polymerization. Nat Immunol 2011; 12(10): 1010-1016.

17 Alnemri ES, Livingston DJ, Nicholson DW, Salvesen G, Thornberry NA, Wong WW et al. Human ICE/CED-3 protease nomenclature. Cell 1996; 87(2): 171.

18 Lopez-Castejon G, Brough D. Understanding the mechanism of IL-1beta secretion. Cytokine Growth Factor Rev 2011; 22(4): 189-195.

19 Dinarello CA. Immunological and inflammatory functions of the interleukin-1 family. Annu Rev Immunol 2009; 27: 519-550.

20 Voronov E, Shouval DS, Krelin Y, Cagnano E, Benharroch $\mathrm{D}$, Iwakura $Y$ et al. IL-1 is required for tumor invasiveness and angiogenesis. Proc Natl Acad Sci USA 2003; 100(5): 2645-2650.

21 Dinarello CA. Biologic basis for interleukin-1 in disease. Blood 1996; 87(6): 2095-2147.

22 Opdenakker G, Van den Steen PE, Dubois B, Nelissen I, Van Coillie E, Masure S et al. Gelatinase B functions as regulator and effector in leukocyte biology. J Leukocyte Biol 2001; 69(6): 851-859.

23 Finger JN, Lich JD, Dare LC, Cook MN, Brown KK, Duraiswami $C$ et al. Autolytic proteolysis within the function to find domain (FIIND) is required for NLRP1 inflammasome activity. J Biol Chem 2012; 287(30): 25030-25037.

24 Hoffman HM, Mueller JL, Broide DH, Wanderer AA, Kolodner RD. Mutation of a new gene encoding a putative pyrin-like protein causes familial cold autoinflammatory syndrome and Muckle-Wells syndrome. Nat Genet 2001; 29 (3): 301-305.

25 Ichinohe T, Pang IK, Iwasaki A. Influenza virus activates inflammasomes via its intracellular M2 ion channel. Nat Immunol 2010; 11(5): 404-410.

26 Shimada K, Crother TR, Karlin J, Chen S, Chiba N, Ramanujan VK et al. Caspase-1 dependent IL-1beta secretion is critical for host defense in a mouse model of Chlamydia pneumoniae lung infection. PLoS ONE 2011; 6 (6): e21477.

27 Dostert C, Petrilli V, Van Bruggen R, Steele C, Mossman BT, Tschopp J. Innate immune activation through Nalp3 inflammasome sensing of asbestos and silica. Science (New York, NY) 2008; 320(5876): 674-677.

28 Mariathasan S, Weiss DS, Newton K, McBride J, O'Rourke $\mathrm{K}$, Roose-Girma $\mathrm{M}$ et al. Cryopyrin activates the inflammasome in response to toxins and ATP. Nature 2006; 440(7081): 228-232.

29 Broz P, Dixit VM. Inflammasomes: mechanism of assembly, regulation and signalling. Nat Rev Immunol 2016; 16(7): 407-420.

30 He Y, Zeng MY, Yang D, Motro B, Nunez G. NEK7 is an essential mediator of NLRP3 activation downstream of potassium efflux. Nature 2016; 530(7590): 354-357.

31 Shi H, Wang Y, Li X, Zhan X, Tang M, Fina M et al. NLRP3 activation and mitosis are mutually exclusive events coordinated by NEK7, a new inflammasome component. Nat Immunol 2016; 17(3): 250-258.

32 Sutterwala FS, Mijares LA, Li L, Ogura Y, Kazmierczak BI, Flavell RA. Immune recognition of Pseudomonas aeruginosa mediated by the IPAF/NLRC4 inflammasome. J Exp Med 2007; 204(13): 3235-3245.

33 Poyet JL, Srinivasula SM, Tnani M, Razmara M, FernandesAlnemri T, Alnemri ES. Identification of Ipaf, a human 
caspase-1-activating protein related to Apaf-1. J Biol Chem 2001; 276(30): 28309-28313.

34 Mao K, Chen S, Wang Y, Zeng Y, Ma Y, Hu Y et al. betaarrestin1 is critical for the full activation of NLRP3 and NLRC4 inflammasomes. J Immunol 2015; 194(4): 1867-1873.

35 Miao EA, Ernst RK, Dors M, Mao DP, Aderem A. Pseudomonas aeruginosa activates caspase 1 through Ipaf. Proc Natl Acad Sci USA 2008; 105(7): 2562-2567.

36 Kofoed EM, Vance RE. Innate immune recognition of bacterial ligands by NAIPs determines inflammasome specificity. Nature 2011; 477(7366): 592-595.

37 Rathinam VA, Jiang Z, Waggoner SN, Sharma S, Cole LE, Waggoner $\mathrm{L}$ et al. The AIM2 inflammasome is essential for host defense against cytosolic bacteria and DNA viruses. Nat Immunol 2010; 11(5): 395-402.

38 Fernandes-Alnemri T, Yu JW, Juliana C, Solorzano L, Kang $\mathrm{S}, \mathrm{Wu} \mathrm{J}$ et al. The AIM2 inflammasome is critical for innate immunity to Francisella tularensis. Nat Immunol 2010; 11(5): 385-393.

39 Wu YH, Kuo WC, Wu YJ, Yang KT, Chen ST, Jiang ST et al. Participation of c-FLIP in NLRP3 and AIM2 inflammasome activation. Cell Death Differ 2014; 21(3): 451-461.

40 Master SS, Rampini SK, Davis AS, Keller C, Ehlers S, Springer B et al. Mycobacterium tuberculosis prevents inflammasome activation. Cell Host Microbe 2008; 3(4): 224-232.

41 Allen IC, Scull MA, Moore CB, Holl EK, McElvaniaTeKippe E, Taxman DJ et al. The NLRP3 inflammasome mediates in vivo innate immunity to influenza A virus through recognition of viral RNA. Immunity 2009; 30(4): 556-565.

42 Pontillo A, Brandao LA, Guimaraes RL, Segat L, Athanasakis E, Crovella S. A 3'UTR SNP in NLRP3 gene is associated with susceptibility to HIV-1 infection. J Acquir Immune Defic Syndr (1999) 2010; 54(3): 236-240.

43 Gross O, Poeck H, Bscheider M, Dostert C, Hannesschlager $\mathrm{N}$, Endres $\mathrm{S}$ et al. Syk kinase signalling couples to the Nlrp3 inflammasome for anti-fungal host defence. Nature 2009; 459(7245): 433-436.

44 Shinkai K, McCalmont TH, Leslie KS. Cryopyrin-associated periodic syndromes and autoinflammation. Clin Exp Dermatol 2008; 33(1): 1-9.

45 Chi W, Li F, Chen H, Wang Y, Zhu Y, Yang X et al. Caspase8 promotes NLRP1/NLRP3 inflammasome activation and IL-1beta production in acute glaucoma. Proc Natl Acad Sci USA 2014; 111(30): 11181-11186.

46 Chavarria-Smith J, Vance RE. The NLRP1 inflammasomes. Immunol Rev 2015; 265(1): 22-34.

47 Yang X, Luo C, Cai J, Powell DW, Yu D, Kuehn MH et al. Neurodegenerative and inflammatory pathway components linked to TNF-alpha/TNFR1 signaling in the glaucomatous human retina. Invest Ophthalmol Vis Sci 2011; 52(11): 8442-8454.

48 Yang H, Antoine DJ, Andersson U, Tracey KJ. The many faces of HMGB1: molecular structure-functional activity in inflammation, apoptosis, and chemotaxis. J Leukocyte Biol 2013; 93(6): 865-873.

49 Schallenberg M, Prokosch V, Thanos S. Regulation of retinal proteome by topical antiglaucomatous eye drops in an inherited glaucoma rat model. PLoS ONE 2012; 7(7): e33593.

50 Harris HE, Andersson U, Pisetsky DS. HMGB1: a multifunctional alarmin driving autoimmune and inflammatory disease. Nat Rev Rheumatol 2012; 8(4): 195-202.

51 Andersson U, Tracey KJ. HMGB1 is a therapeutic target for sterile inflammation and infection. Annu Rev Immunol 2011; 29: 139-162.

52 Chi W, Chen H, Li F, Zhu Y, Yin W, Zhuo Y. HMGB1 promotes the activation of NLRP3 and caspase-8 inflammasomes via NF-kappaB pathway in acute glaucoma. J Neuroinflamm 2015; 12: 137.

53 Tezel G, Yang X, Luo C, Kain AD, Powell DW, Kuehn MH et al. Oxidative stress and the regulation of complement activation in human glaucoma. Invest Ophthalmol Vis Sci 2010; 51(10): 5071-5082.

54 Tezel G, Luo C, Yang X. Accelerated aging in glaucoma: immunohistochemical assessment of advanced glycation end products in the human retina and optic nerve head. Invest Ophthalmol Vis Sci 2007; 48(3): 1201-1211.

55 Puyang Z, Feng L, Chen H, Liang P, Troy JB, Liu X. Retinal ganglion cell loss is delayed following optic nerve crush in NLRP3 knockout mice. Sci Rep. 2016; 6: 20998.

56 Perrone L, Devi TS, Hosoya K, Terasaki T, Singh LP. Thioredoxin interacting protein (TXNIP) induces inflammation through chromatin modification in retinal capillary endothelial cells under diabetic conditions. J Cell Physiol 2009; 221(1): 262-272.

57 Devi TS, Lee I, Huttemann M, Kumar A, Nantwi KD, Singh LP. TXNIP links innate host defense mechanisms to oxidative stress and inflammation in retinal Muller glia under chronic hyperglycemia: implications for diabetic retinopathy. Exp Diabetes Res 2012; 2012: 438238.

58 Klein ML, Ferris FL 3rd, Armstrong J, Hwang TS, Chew EY, Bressler SB et al. Retinal precursors and the development of geographic atrophy in age-related macular degeneration. Ophthalmology 2008; 115(6): 1026-1031.

59 Doyle SL, Campbell M, Ozaki E, Salomon RG, Mori A, Kenna PF et al. NLRP3 has a protective role in age-related macular degeneration through the induction of IL-18 by drusen components. Nat Med 2012; 18(5): 791-798.

60 Tseng WA, Thein T, Kinnunen K, Lashkari K, Gregory MS, D'Amore PA et al. NLRP3 inflammasome activation in retinal pigment epithelial cells by lysosomal destabilization: implications for age-related macular degeneration. Invest Ophthalmol Vis Sci 2013; 54(1): 110-120.

61 Kauppinen A, Niskanen H, Suuronen T, Kinnunen K, Salminen A, Kaarniranta K. Oxidative stress activates NLRP3 inflammasomes in ARPE-19 cells-implications for age-related macular degeneration (AMD). Immunol Lett 2012; 147(1-2): 29-33.

62 Iyer SS, Pulskens WP, Sadler J, Butter LM, Teske GJ, Ulland TK et al. Necrotic cells trigger a sterile inflammatory response through the Nlrp3 inflammasome. Proc Natl Acad Sci USA 2009; 106(48): 20388-20393.

63 Hageman GS, Mullins RF. Molecular composition of drusen as related to substructural phenotype. Mol Vision 1999; 5: 28.

64 Mariner PD, Walters RD, Espinoza CA, Drullinger LF, Wagner SD, Kugel JF et al. Human Alu RNA is a modular transacting repressor of mRNA transcription during heat shock. Mol Cell 2008; 29(4): 499-509.

65 Tarallo V, Hirano Y, Gelfand BD, Dridi S, Kerur N, Kim Y et al. DICER1 loss and Alu RNA induce age-related macular degeneration via the NLRP3 inflammasome and MyD88. Cell 2012; 149(4): 847-859. 
66 Kim Y, Tarallo V, Kerur N, Yasuma T, Gelfand BD, BastosCarvalho A et al. DICER1/Alu RNA dysmetabolism induces Caspase-8-mediated cell death in age-related macular degeneration. Proc Natl Acad Sci USA 2014; 111(45): 16082-16087.

67 Gross O, Thomas CJ, Guarda G, Tschopp J. The inflammasome: an integrated view. Immunol rev 2011; 243 (1): 136-151.

68 Brandstetter C, Mohr LK, Latz E, Holz FG, Krohne TU. Light induces NLRP3 inflammasome activation in retinal pigment epithelial cells via lipofuscin-mediated photooxidative damage. J Mol Med 2015; 93(8): 905-916.

69 Hirano Y, Yasuma T, Mizutani T, Fowler BJ, Tarallo V, Yasuma R et al. IL18 is not therapeutic for neovascular agerelated macular degeneration. Nat Med 2014; 20(12): 1372-1375.

70 Dobson DE, Kambe A, Block E, Dion T, Lu H, Castellot JJ Jr. et al. 1-Butyryl-glycerol: a novel angiogenesis factor secreted by differentiating adipocytes. Cell 1990; 61(2): 223-230.

71 Ozaki E, Campbell M, Doyle SL. Targeting the NLRP3 inflammasome in chronic inflammatory diseases: current perspectives. J Inflamm Res 2015; 8: 15-27.

72 Zheng Q, Ren Y, Reinach PS, She Y, Xiao B, Hua S et al. Reactive oxygen species activated NLRP3 inflammasomes prime environment-induced murine dry eye. Exp Eye Res 2014; 125: 1-8.

73 Saavedra PH, Demon D, Van Gorp H, Lamkanfi M. Protective and detrimental roles of inflammasomes in disease. Semin Immunopathol 2015; 37(4): 313-322.

74 Liang L, Tan X, Zhou Q, Zhu Y, Tian Y, Yu H et al. IL-1beta triggered by peptidoglycan and lipopolysaccharide through TLR2/4 and ROS-NLRP3 inflammasomedependent pathways is involved in ocular Behcet's disease. Invest Ophthalmol Vis Sci 2013; 54(1): 402-414.

75 Yuksel S, Eren E, Hatemi G, Sahillioglu AC, Gultekin Y, Demiroz D et al. Novel NLRP3/cryopyrin mutations and pro-inflammatory cytokine profiles in Behcet's syndrome patients. Int Immunol 2014; 26(2): 71-81.

76 Asgari E, Le Friec G, Yamamoto H, Perucha E, Sacks SS, Kohl J et al. C3a modulates IL-1beta secretion in human monocytes by regulating ATP efflux and subsequent NLRP3 inflammasome activation. Blood 2013; 122(20): 3473-3481.

77 Lemp MA, Baudouin C, Baum J, Dogru M, Foulks GN, Kinoshita $\mathrm{S}$ et al. The definition and classification of dry eye disease: report of the Definition and Classification Subcommittee of the International Dry Eye WorkShop (2007). Ocul Surf 2007; 5(2): 75-92.

78 McGilligan VE, Gregory-Ksander MS, Li D, Moore JE, Hodges RR, Gilmore MS et al. Staphylococcus aureus activates the NLRP3 inflammasome in human and rat conjunctival goblet cells. PLOS ONE 2013; 8(9): e74010.

79 Ewald SE, Chavarria-Smith J, Boothroyd JC. NLRP1 is an inflammasome sensor for Toxoplasma gondii. Infect Immun 2014; 82(1): 460-468.

80 Karthikeyan RS, Priya JL, Leal SM Jr., Toska J, Rietsch A, Prajna V et al. Host response and bacterial virulence factor expression in Pseudomonas aeruginosa and Streptococcus pneumoniae corneal ulcers. PLoS ONE 2013; 8(6): e64867.

81 Pearlman E, Sun Y, Roy S, Karmakar M, Hise AG, SzczotkaFlynn $L$ et al. Host defense at the ocular surface. Int Rev Immunol 2013; 32(1): 4-18.
82 Malley R, Henneke P, Morse SC, Cieslewicz MJ, Lipsitch M, Thompson CM et al. Recognition of pneumolysin by Tolllike receptor 4 confers resistance to pneumococcal infection. Proc Natl Acad Sci USA 2003; 100(4): 1966-1971.

83 Fang R, Tsuchiya K, Kawamura I, Shen Y, Hara H, Sakai S et al. Critical roles of ASC inflammasomes in caspase-1 activation and host innate resistance to Streptococcus pneumoniae infection. J Immunol 2011; 187(9): 4890-4899.

84 Khan S, Cole N, Hume EB, Garthwaite L, Conibear TC, Miles DH et al. The role of CXC chemokine receptor 2 in Pseudomonas aeruginosa corneal infection. J Leukocyte Biol 2007; 81(1): 315-318.

85 McClellan SA, Huang X, Barrett RP, Lighvani S, Zhang Y, Richiert D et al. Matrix metalloproteinase-9 amplifies the immune response to Pseudomonas aeruginosa corneal infection. Invest Ophthalmol Vis Sci 2006; 47(1): 256-264.

86 Van den Steen PE, Proost P, Wuyts A, Van Damme J, Opdenakker G. Neutrophil gelatinase B potentiates interleukin- 8 tenfold by aminoterminal processing, whereas it degrades CTAP-III, PF-4, and GRO-alpha and leaves RANTES and MCP-2 intact. Blood 2000; 96(8): 2673-2681.

87 Thakur A, Barrett RP, Hobden JA, Hazlett LD. Caspase-1 inhibitor reduces severity of pseudomonas aeruginosa keratitis in mice. Invest Ophthalmol Vis Sci 2004; 45(9): 3177-3184.

88 Thakur A, Xue M, Stapleton F, Lloyd AR, Wakefield D, Willcox MD. Balance of pro- and anti-inflammatory cytokines correlates with outcome of acute experimental Pseudomonas aeruginosa keratitis. Infect Immun 2002; 70(4): 2187-2197.

89 Sola-Villa D, Camacho M, Sola R, Soler M, Diaz JM, Vila L. IL-1beta induces VEGF, independently of PGE2 induction, mainly through the PI3-K/mTOR pathway in renal mesangial cells. Kidney Int 2006; 70(11): 1935-1941.

90 Pavilack MA, Elner VM, Elner SG, Todd RF 3rd, Huber AR. Differential expression of human corneal and perilimbal ICAM-1 by inflammatory cytokines. Invest Ophthalmol Vis Sci 1992; 33(3): 564-573.

91 Opdenakker G, Van den Steen PE, Van Damme J, Gelatinase B. a tuner and amplifier of immune functions. Trends Immunol 22(10): 571-579.

92 Opdenakker G, Masure S, Grillet B, Van Damme J. Cytokine-mediated regulation of human leukocyte gelatinases and role in arthritis. Lymphokine Cytokine Res 1991; 10(4): 317-324.

93 Schonbeck U, Mach F, Libby P. Generation of biologically active IL-1 beta by matrix metalloproteinases: a novel caspase-1-independent pathway of IL-1 beta processing. J Immunol 1998; 161(7): 3340-3346.

94 Jabir MS, Hopkins L, Ritchie ND, Ullah I, Bayes HK, Li D et al. Mitochondrial damage contributes to Pseudomonas aeruginosa activation of the inflammasome and is downregulated by autophagy. Autophagy 2015; 11(1): 166-182.

95 Arlehamn CS, Evans TJ. Pseudomonas aeruginosa pilin activates the inflammasome. Cell Microbiol 2011; 13(3): 388-401.

96 Geng S, Ye JJ, Zhao JL, Li TS, Han Y. Cytomegalovirus retinitis associated with acquired immunodeficiency syndrome. Chin Med J 2011; 124(8): 1134-1138.

97 Ho M. Advances in understanding cytomegalovirus infection after transplantation. Transplant Proc 1994; 26(5 Suppl 1): 7-11. 
98 Chien H, Dix RD. Evidence for multiple cell death pathways during development of experimental cytomegalovirus retinitis in mice with retrovirus-induced immunosuppression: apoptosis, necroptosis, and pyroptosis. J Virol 2012; 86(20): 10961-10978.

99 Marchetti C, Chojnacki J, Toldo S, Mezzaroma E, Tranchida $\mathrm{N}$, Rose SW et al. A novel pharmacologic inhibitor of the NLRP3 inflammasome limits myocardial injury after ischemia-reperfusion in the mouse. Journal of cardiovascular pharmacology 2014; 63(4): 316-22.

100 Coll RC, Robertson AA, Chae JJ, Higgins SC, MunozPlanillo R, Inserra MC et al. A small-molecule inhibitor of the NLRP3 inflammasome for the treatment of inflammatory diseases 2015; 21(3): 248-55.

101 Yan Y, Jiang W, Liu L, Wang X, Ding C, Tian Z et al. Dopamine controls systemic inflammation through inhibition of NLRP3 inflammasome. Cell 2015; 160(1-2): 62-73.

102 Mao K, Chen S, Chen M, Ma Y, Wang Y, Huang B et al. Nitric oxide suppresses NLRP3 inflammasome activation and protects against LPS-induced septic shock. Cell research 2013; 23(2): 201-12.

103 Maier NK, Crown D, Liu J, Leppla SH, Moayeri M.. Arsenic trioxide and other arsenical compounds inhibit the NLRP1, NLRP3, and NAIP5/NLRC4 inflammasomes. Journal of immunology (Baltimore, Md: 1950) 2014; 192(2): 763-70.

104 Budai MM, Varga A, Milesz S, Tozser J, Benko S. Aloe vera downregulates LPS-induced inflammatory cytokine production and expression of NLRP3 inflammasome in human macrophages. Molecular immunology 2013; 56(4): $471-9$.

105 Hu Y, Mao K, Zeng Y, Chen S, Tao Z, Yang C et al. Tripartite-motif protein 30 negatively regulates NLRP3 inflammasome activation by modulating reactive oxygen species production. Journal of immunology (Baltimore, Md: 1950) 2010; 185(12): 7699-705.

106 Guarda G, Braun M, Staehli F, Tardivel A, Mattmann C, Forster I et al. Type I interferon inhibits interleukin-1 production and inflammasome activation. Immunity 2011; 34(2): 213-23.

107 Kaminski JJ, Schattgen SA, Tzeng TC, Bode C, Klinman DM, Fitzgerald KA.. Synthetic oligodeoxynucleotides containing suppressive TTAGGG motifs inhibit AIM2 inflammasome activation. Journal of immunology (Baltimore, Md: 1950) 2013; 191(7): 3876-83

108 Lamkanfi M, Mueller JL, Vitari AC, Misaghi S, Fedorova A, Deshayes K et al. Glyburide inhibits the Cryopyrin/Nalp3 inflammasome. The Journal of cell biology 2009; 187(1): 61-70.
109 Ahn H, Kim J, Jeung EB, Lee GS.. Dimethyl sulfoxide inhibits NLRP3 inflammasome activation. Immunobiology 2014; 219(4): 315-22.

110 Marty-Roix R, Lien E.. (De-) oiling inflammasomes. Immunity 2013; 38(6): 1088-90.

111 Juliana C, Fernandes-Alnemri T, Wu J, Datta P, Solorzano L, Yu JW et al. Anti-inflammatory compounds parthenolide and Bay 11-7082 are direct inhibitors of the inflammasome. The Journal of biological chemistry 2010; 285(13): 9792-802.

112 He Y, Varadarajan S, Munoz-Planillo R. Burberry A, Nakamura Y, Nunez G. 3,4-methylenedioxy-betanitrostyrene inhibits NLRP3 inflammasome activation by blocking assembly of the inflammasome. The Journal of biological chemistry 2014; 289(2): 1142-50.

113 Hua K-F, Chou J-C, Lam Y, Tasi Y-L, Chen A, Ka S-M et al. Polyenylpyrrole Derivatives Inhibit NLRP3 Inflammasome Activation and Inflammatory Mediator Expression by Reducing Reactive Oxygen Species Production and Mitogen-Activated Protein Kinase Activation. PloS one 2013; 8(10): e76754.

114 Nakahira K, Haspel JA, Rathinam VAK, Lee S-J, Dolinay T, Lam HC et al. Autophagy proteins regulate innate immune response by inhibiting NALP3 inflammasome-mediated mitochondrial DNA release. Nature immunology 2011; 12(3): 222-30.

115 Bauernfeind F, Rieger A, Schildberg FA, Knolle PA, Schmid-Burgk JL, Hornung V.. NLRP3 inflammasome activity is negatively controlled by miR-223. Journal of immunology (Baltimore, Md: 1950) 2012; 189(8): 4175-81.

116 Haneklaus M, Gerlic M, Kurowska-Stolarska M, Rainey AA, Pich D, McInnes IB et al. Cutting edge: miR-223 and EBV miR-BART15 regulate the NLRP3 inflammasome and IL-1beta production. Journal of immunology (Baltimore, Md: 1950) 2012; 189(8): 3795-9.

117 Giguère PM, Gall BJ, Ezekwe EAD, Laroche G, Buckley BK, Kebaier $C$ et al. G Protein Signaling Modulator-3 Inhibits the Inflammasome Activity of NLRP3. The Journal of biological chemistry 2014; 289(48): 33245-57.

118 Jin J, Yu Q, Han C, Hu X, Xu S, Wang Q et al. LRRFIP2 negatively regulates NLRP3 inflammasome activation in macrophages by promoting Flightless-I-mediated caspase-1 inhibition. Nature Communications 2013; 4: 2075.

119 Deroide N, Li X, Lerouet D, Van Vré E, Baker L, Harrison J et al. MFGE8 inhibits inflammasome-induced IL-1 $\beta$ production and limits postischemic cerebral injury. The Journal of clinical investigation 2013; 123(3): 1176-81. 